\title{
Intraoperative lactic acid concentration during liver transplantation and cutoff values to predict early mortality: a retrospective analysis of 3,338 cases
}

\author{
Kyoung-Sun Kim', Sang-Ho Lee', Bo-Hyun Sang ${ }^{2}$, and \\ Gyu-Sam Hwang ${ }^{1}$
}

Received May 31, 2021

Revised September 7, 2021

Accepted September 10, 2021

\section{Corresponding author}

Gyu-Sam Hwang, M.D., Ph.D.

Department of Anesthesiology and

Pain Medicine, Laboratory for

Cardiovascular Dynamics, Asan

Medical Center, University of Ulsan

College of Medicine, 88 Olympic-ro

43-gil, Songpa-gu, Seoul 05505,

Korea

Tel: 82-2-3010-3989

Fax: 82-2-470-1363

E-mail: kshwang@amc.seoul.kr
'Department of Anesthesiology and Pain Medicine, Laboratory for Cardiovascular Dynamics, Asan Medical Center, University of Ulsan College of Medicine, Seoul, ${ }^{2}$ Department of Anesthesiology and Pain Medicine, CHA Bundang Medical Center, CHA University School of Medicine, Seongnam, Korea

Background: We aimed to explore the distribution of intraoperative lactic acid (LA) level during liver transplantation (LT) and determine the optimal cutoff values to predict post-LT 30-day and 90-day mortality.

Methods: Intraoperative LA data from 3,338 patients were collected between 2008 to 2019 and all-cause mortalities within 30 and 90 days were retrospectively reviewed. Of the three LA levels measured during preanhepatic, anhepatic, and neohepatic phase of LT, the peak LA level was selected to explore the distribution and predict early post-LT mortality. To determine the best cutoff values of LA, we used a classification and regression tree algorithm and maximally selected rank statistics with the smallest $P$ value.

Results: The median intraoperative LA level was $4.4 \mathrm{mmol} / \mathrm{L}$ (range: $0.5-34.7$, interquartile range: 3.0-6.2 mmol/L). Of the 3,338 patients, 1,884 (56.4\%) had LA levels $>4.0 \mathrm{mmol} / \mathrm{L}$ and $188(5.6 \%)$ had LA levels $>10 \mathrm{mmol} / \mathrm{L}$. Patients with LA levels $>16.7 \mathrm{mmol} / \mathrm{L}$ and 13.5-16.7 mmol/L showed significantly higher 30-day mortality rates of $58.3 \%$ and $21.2 \%$, respectively. For the prediction of the 90-day mortality, $8.4 \mathrm{mmol} / \mathrm{L}$ of intraoperative LA was the best cutoff value.

Conclusions: Approximately $6 \%$ of the $L T$ recipients showed intraoperative hyperlactatemia of $>10 \mathrm{mmol} / \mathrm{L}$ during $\mathrm{LT}$, and those with LA > $8.4 \mathrm{mmol} / \mathrm{L}$ were associated with significantly higher early post-LT mortality.

Keywords: Intraoperative hyperlactatemia; Lactic acid; Liver transplantation; Mortality.

\section{INTRODUCTION}

The liver plays a key role in lactate metabolism. Hyperlactatemia is generally considered as an increase in lactate production due to anaerobic metabolism in a state of reduced organ perfusion. However, measured lactic acid (LA) con- centrations are the sum of metabolic and catabolic process, therefore hyperlactatemia may be due to an increase in production or a reduction in clearance in liver disease $[1,2]$.

Additionally, the liver can be transformed into a lactate-producing organ in cases of hypoxia, sepsis, or liver surgery [1-4]. Therefore, given the enhanced lactate produc-

This is an Open Access article distributed under the terms of the Creative Commons Attribution Non-Commercial License (http://creativecommons.org/licenses/by-nc/4.0) which permits unrestricted non-commercial use, distribution, and reproduction in any medium, provided the original work is properly cited.

Copyright (C) the Korean Society of Anesthesiologists, 2022 
tion, reduction in clearance, and lactate-producing liver itself after reperfusion of the allograft, extremely high intraoperative LA levels are expected in patients undergoing liver transplantation (LT). However, compared to those of critically ill patients, characteristics of intraoperative LA concentrations during LT have been poorly studied in a large cohort of LTs. In addition, although there are studies that found that lactate clearance shortly after reperfusion of an allograft is associated with short-term prognosis [5-7], research on cutoff levels of intraoperative LA to predict early mortality remains poorly investigated $[8,9]$.

To better understand the changes in LA concentration during LT, we thoroughly explored both preoperative and intraoperative LA and, furthermore, determined optimal cutoff values of intraoperative LA to predict post-LT 30-day and 90-day mortality.

\section{MATERIALS AND METHODS}

\section{Study population}

The Institutional Review Board approved the study design and a waiver of informed consent for participants (no. 20210664). Data from the institution's LT Registry, which prospectively registered patients who underwent LT, was extracted via the software, a fully computerized and automatic data extraction program. From January 2008 to December 2019 , there were 4,604 potentially eligible LT recipients. Among them, 3,338 patients with measured intraoperative LA levels were chosen. We included the majority of heterogenous LT recipients because we aimed to characterize intraoperative LA and determine optimal cutoff values of hyperlactatemia to predict early post-LT mortality.

\section{Data collection}

Patient demographics, medical history, Model for Endstage Liver Disease score (MELDs), and preoperative laboratory variables were obtained automatically using the hospital software. All-cause mortality data were obtained from patients' electronic medical records and the updated record of the institution's LT Registry, which regularly follows all the registerd LT recipients.

\section{Measurement of intraoperative LA during LT}

Intraoperative LA levels were measured three times during the preanhepatic, anhepatic, and neohepatic periods as per the institution's routine intraoperative protocol. Of these, the peak level of intraoperative LA was used to analyze its distribution and predict early post-LT mortality. Preoperative LA concentration was also measured before LT as a routine work-up.

\section{Study end-point}

Primary and secondary end-points were 30-day and 90day mortality, respectively.

\section{Statistical analysis}

Data are expressed as the mean \pm standard deviation or median (1st quartile, 3rd quartile) for continuous variables, and numbers and percentages for categorical variables. Analyses between groups were performed using the Student's $t$-test, the Mann-Whiney $U$ test, analysis of variance, or the Kruskal-Wallis test for continuous variables and the $\chi^{2}$ test or Fisher's exact test for categorical variables, as appropriate. The Kolmogorov-Smirnov test was used to test the normality assumption. To determine the best cutoff values of LA, we used a classification and regression tree (CART) algorithm of recursive partitioning and maximally selected rank statistics with the smallest $P$ value ('caret' and 'maxstat' R package).

Briefly, in maximally selected rank statistics. The prognostic cutoff point was determined by evaluating every possible cutoff point classifying all patients into two groups according to their level and selecting the most discriminant threshold for death, corresponding to the minimum $\mathrm{P}$ value according to the log-rank test [10-12]. The KaplanMeier (KM) survival curve was used to depict the risk of 30day and 90-day mortality.

\section{RESULTS}

The mean age of the 3,338 LT recipients included was 53.3 \pm 9.0 years. Of the patients, $2,443(73.2 \%)$ were men. The mean MELDs was $18.2 \pm 10.9$ (Table 1 ). The primary causes of liver disease were virus-related liver cirrhosis (63.1\%) and alcoholic liver disease (20.3\%), followed by others (18\%).

\section{Distribution of preoperative and intraoperative LA}

The preoperative median LA level was $1.9 \mathrm{mmol} / \mathrm{L}$ (range: 
Table 1. Patients' Demographics according to the Intraoperative Lactic Acid Levels

\begin{tabular}{|c|c|c|c|c|}
\hline Variable & $\mathrm{LA} \leq 8.4 \mathrm{mmol} / \mathrm{L}(\mathrm{n}=2,997)$ & $\mathrm{LA}>8.4 \mathrm{mmol} / \mathrm{L}(\mathrm{n}=341)$ & Total $(n=3,338)$ & $P$ value \\
\hline \multicolumn{5}{|l|}{ Demographic data } \\
\hline Age (yr) & $53.2 \pm 9.1$ & $54.0 \pm 8.8$ & $53.3 \pm 9.0$ & 0.123 \\
\hline Sex, male & $2,171(72.4)$ & $272(79.8)$ & $2,443(73.2)$ & 0.005 \\
\hline Body mass index $\left(\mathrm{kg} / \mathrm{m}^{2}\right)$ & $24.2 \pm 3.7$ & $24.8 \pm 3.7$ & $24.3 \pm 3.7$ & 0.003 \\
\hline Diabetes & $731(24.4)$ & $69(20.2)$ & $800(24.0)$ & 0.102 \\
\hline Hypertension & $559(18.7)$ & $60(17.6)$ & $619(18.5)$ & 0.688 \\
\hline MELD score & $18.1 \pm 10.8$ & $18.9 \pm 12.0$ & $18.2 \pm 10.9$ & 0.262 \\
\hline MELDs & & & & 0.138 \\
\hline MELD $<15$ & $1,619(54.0)$ & $188(55.1)$ & $1,807(54.1)$ & \\
\hline MELD 15-35 & $1,062(35.4)$ & $107(31.4)$ & $1,169(35.0)$ & \\
\hline MELD > 35 & $316(10.5)$ & $46(13.5)$ & $362(10.8)$ & \\
\hline \multicolumn{5}{|l|}{ Causes for liver disease } \\
\hline Viral & $1,874(62.5)$ & $231(67.7)$ & $2,105(63.1)$ & 0.067 \\
\hline Alcoholic & $620(20.7)$ & $56(16.4)$ & $676(20.3)$ & 0.074 \\
\hline Biliary & $99(3.3)$ & $4(1.2)$ & $103(3.1)$ & 0.047 \\
\hline Others & $543(18.1)$ & $57(16.7)$ & $600(18.0)$ & 0.572 \\
\hline Malignancy & $1,363(45.5)$ & $185(54.3)$ & $1,548(46.4)$ & 0.003 \\
\hline \multicolumn{5}{|l|}{ Comorbidities } \\
\hline Fulminant hepatic failure & $136(4.5)$ & $25(7.3)$ & $161(4.8)$ & 0.032 \\
\hline Intractable ascites & $951(31.7)$ & $96(28.2)$ & $1,047(31.4)$ & 0.198 \\
\hline Hepatic encephalopathy & $473(15.8)$ & $64(18.8)$ & $537(16.1)$ & 0.179 \\
\hline Pleural effusion & $401(13.4)$ & $41(12.0)$ & $442(13.2)$ & 0.538 \\
\hline Spontaneous bacterial peritonitis & $123(4.1)$ & $15(4.4)$ & $138(4.1)$ & 0.908 \\
\hline \multicolumn{5}{|l|}{ Laboratory variables } \\
\hline Intraoperative & $4.1(2.9,5.6)$ & $10.4(9.2,12.2)$ & $4.4(3.0,6.2)$ & $<0.001$ \\
\hline \multicolumn{5}{|l|}{ Lactic acid (mmol/L) } \\
\hline Hemoglobin (g/dl) & $10.4(8.9,12.2)$ & $10.7(9.0,12.7)$ & $10.4(8.9,12.3)$ & 0.052 \\
\hline Leukocytes $\left(\times 10^{3} / \mu \mathrm{l}\right)$ & $3.6(2.5,5.3)$ & $3.5(2.5,5.6)$ & $3.6(2.5,5.3)$ & 0.739 \\
\hline Platelet count $\left(\times 10^{3} / \mu \mathrm{l}\right)$ & $61(42,94)$ & $60(41,91)$ & $61(42,94)$ & 0.786 \\
\hline Total bilirubin (mg/dl) & $2.1(1.0,9.6)$ & $2.0(1.8,4.8)$ & $2.1(1.0,9.8)$ & 0.844 \\
\hline Albumin (g/dl) & $3.1(2.7,3.5)$ & $3.1(2.7,3.6)$ & $3.1(2.7,3.5)$ & 0.158 \\
\hline Prothrombin time (INR) & $1.4(1.2,1.8)$ & $1.4(1.2,1.9)$ & $1.4(1.2,1.9)$ & 0.507 \\
\hline Creatinine (mg/dl) & $0.80(0.7,1.0)$ & $0.84(0.7,1.1)$ & $0.80(0.7,1.1)$ & 0.012 \\
\hline \multicolumn{5}{|l|}{ Preoperative therapy } \\
\hline Vasopressor support & $145(4.8)$ & $36(10.6)$ & $181(5.4)$ & $<0.001$ \\
\hline Mechanical ventilation & $245(8.2)$ & $54(15.8)$ & $299(9.0)$ & $<0.001$ \\
\hline Renal replacement therapy & $297(9.9)$ & $52(15.2)$ & 349 (10.5) & 0.003 \\
\hline \multicolumn{5}{|l|}{ Operative variables } \\
\hline Deceased-donor & $475(15.8)$ & $51(15.0)$ & $526(15.8)$ & 0.726 \\
\hline Operation time (min) & $740.8 \pm 142.4$ & $754.4 \pm 140.6$ & $742.2 \pm 142.3$ & 0.096 \\
\hline Total ischemic time (min) & $147.5 \pm 71.7$ & $130.5 \pm 53.4$ & $140.8 \pm 65.6$ & $<0.001$ \\
\hline \multicolumn{5}{|l|}{ Transfusion } \\
\hline pRBC (unit) & $11.3 \pm 14.1$ & $13.1 \pm 16.4$ & $11.5 \pm 14.3$ & 0.052 \\
\hline FFP (unit) & $11.7 \pm 14.0$ & $12.7 \pm 14.9$ & $11.8 \pm 14.1$ & 0.193 \\
\hline
\end{tabular}

Values are expressed as mean \pm SD, number (\%), or median (1Q, 3Q). LA: lactic acid, MELD score: Model for End-stage Liver Disease score, pRBC: packed red blood cells, FFP: fresh frozen plasma, INR: international normalized ratio. 
0.4-24.6, interquartile range [IQR]: 1.5-2.6 mmol/L, $\mathrm{n}=$ $1,741)$, but it was markedly increased intraoperatively to a median LA level of $4.4 \mathrm{mmol} / \mathrm{L}$ (range: 0.5-34.7, IQR: 3.0-6.2 $\mathrm{mmol} / \mathrm{L}, \mathrm{n}=3,338$ ) (Fig. 1).

A total of $1,884(56.4 \%)$ patients had intraoperative LA levels $>4.0 \mathrm{mmol} / \mathrm{L}$, and while $188(5.6 \%)$ had intraoperative LA levels > $10 \mathrm{mmol} / \mathrm{L}$.

\section{Distribution of intraoperative LA according to MELDs}

When the patients were grouped according to MELDs of < $15(\mathrm{n}=1,807,54.1 \%), 15-35(\mathrm{n}=1,169,35 \%)$, and $>35(\mathrm{n}=$ $362, \mathrm{n}=10.8 \%$ ), preoperative LA levels increased and separated clearly along with the increase of MELDs (1.8, IQR: 1.4-2.3 vs. 2.0 , IQR: $1.5-2.6$ vs. 2.6 , IQR: $1.9-4.2 \mathrm{mmol} / \mathrm{L}$, respectively; $\mathrm{P}<0.001$ ), whereas, despite the marked increase of intraoperative LA levels, the separation of LA levels were modest and somewhat inversed (4.5, IQR: $3.2-6.3$ vs. 4.3, IQR: 2.9-6.2 vs. 4.1, IQR: 2.7-6.0, respectively; $\mathrm{P}=0.002$ ) compared to preoperative LA (Fig. 2).

\section{Prognostic cutoff values of intraoperative LA}

To predict 30-day all-cause mortality, tree-structured survival analysis using CART of a recursive partitioning algorithm demonstrated that intraoperative LA cutoffs of $13.5 \%$ and $16.7 \%$ were found to be optimal. In addition, maximally selected log-rank statistics of the "maxstat" $\mathrm{R}$ package revealed that LA cutoffs of $8.4 \%$ were the best cutoff for predicting for 90-day all-cause mortality (Fig. 3).

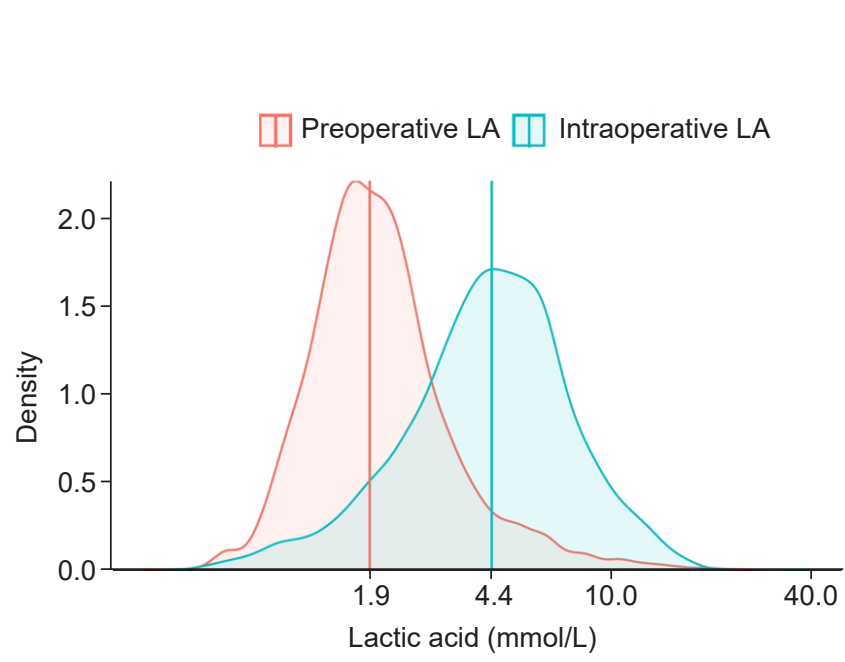

Fig. 1. Distribution of preoperative and intraoperative lactic acid. Vertical line indicate median lactic acid level. LA: lactic acid.

\section{Application of thresholds of LA to predict early mortality}

The 30-day and 90-day mortality rates were $2.5 \%(\mathrm{n}=83)$ and $4.7 \%(\mathrm{n}=157)$, respectively.

When the patients were grouped according to the best cutoff values of $8.4 \mathrm{mmol} / \mathrm{L}$, those with $\mathrm{LA}>8.4 \mathrm{mmol} / \mathrm{L}$ yielded a 30-day mortality rate of $6.7 \%$ and a 90 -day mortality rate of $9.4 \%$ ( $\mathrm{P}<0.001$ ) (Fig. 4). In particular, derived LA cutoffs of $16.7 \%$ and $13.5 \%$ by CART to predict 30-day mortality showed a wide separation of the KM curve. Patients with LA levels > $16.7 \mathrm{mmol} / \mathrm{L}$ and 13.5-16.7 had significantly higher 30 -day mortality rates of $58.3 \%$ and $21.2 \%$, respectively, compared to those with $\mathrm{LA}<13.5 \mathrm{mmol} / \mathrm{L}$, who had a $2.1 \% 30$-day mortality rate (log-rank $\mathrm{P}<0.001$ ) (Fig. 4).
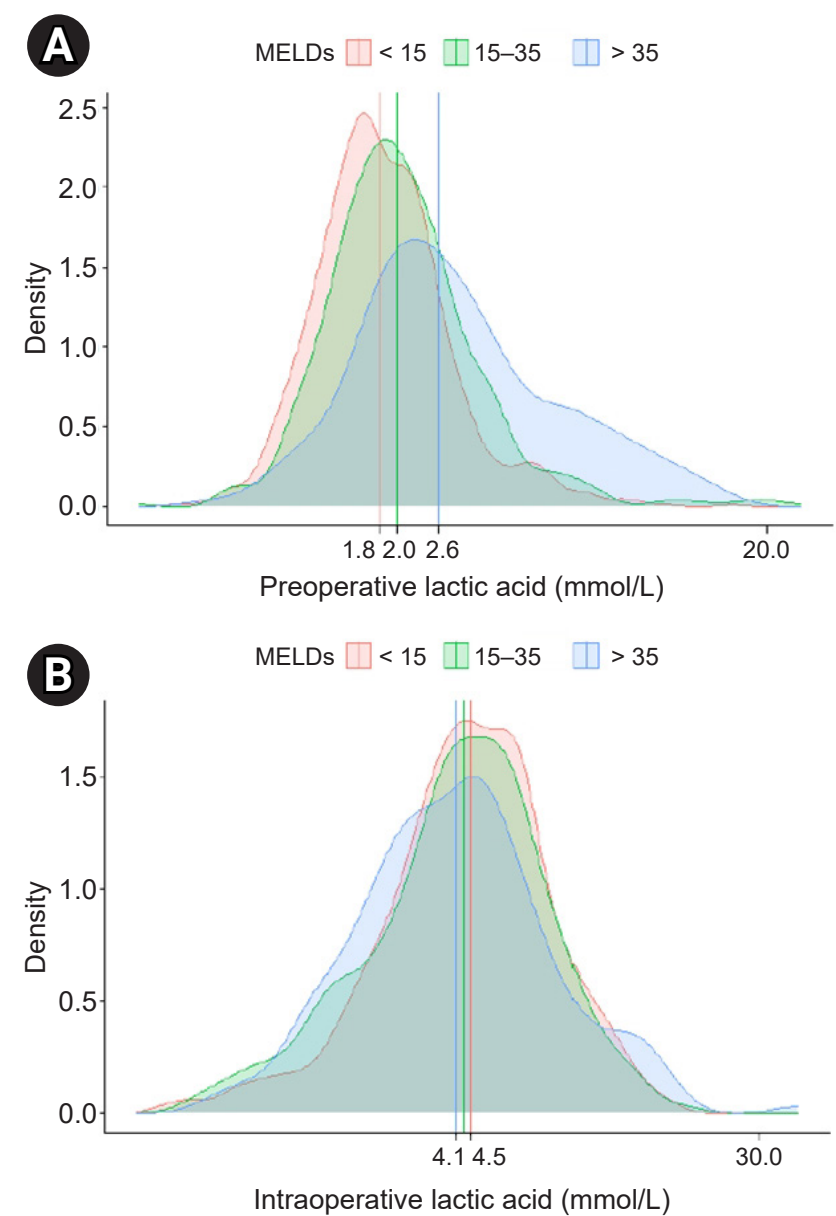

Fig. 2. Distribution of (A) preoperative and (B) intraoperative lactic acid levels according to liver disease severity. Vertical lines indicate median lactic acid. MELDs: model for end-liver disease score. 


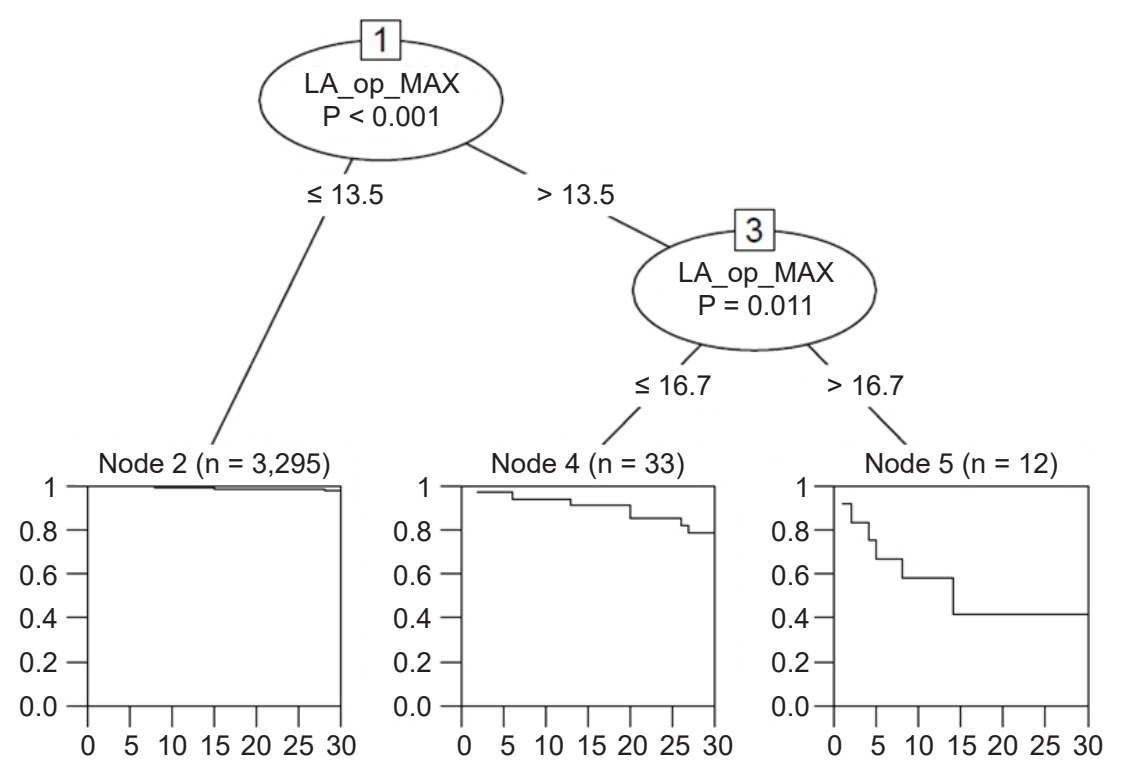

Fig. 3. Decision tree diagram for 30-day mortality, showing intraoperative lactic acid cutoffs of $13.5 \mathrm{mmol} / \mathrm{L}$ and $16.7 \mathrm{mmol} / \mathrm{L}$ as optimal cutoffs in predicting 30-day all-cause mortality. LA: lactic acid, LA_op_MAX: lactic acid_intraoperative_maximal value.

\section{DISCUSSION}

It has long been known that LA levels might reflect critically ill hepatic patients and are independently associated with the short-term mortality affiliated with end-stage liver disease (ESLD) $[6,13,14]$.

In fact, the LA levels and its clearance are known predictors of the outcome of critically ill patients in the intensive care unit [15]. There has been widespread research, especially in septic patients, that evaluate the use of LA as a potential resuscitation marker or prognosticator. Therefore, the Surviving Sepsis Campaign Bundle suggested that if the initial LA is $>2 \mathrm{mmol} / \mathrm{L}$, it should be remeasured within $2-4 \mathrm{~h}$. Moreover, if the LA is $>4 \mathrm{mmol} / \mathrm{L}$ in those with sepsis, the initiation of rapid administration of $>30 \mathrm{ml} / \mathrm{kg}$ crystalloid is strongly recommended in sepsis [16].

However, lactate metabolism in cirrhosis differs substantially from that in patients without hepatic impairment. In the current study, we found that approximately $50 \%$ patients are associated with preoperative LA $>2 \mathrm{mmol} / \mathrm{L}$, confirming that the LA level in patients with ESLD is quite different from those without ESLD. Therefore, management guidelines proposed "repeated measurement of blood lactate levels, even though the interpretation may be complicated by impaired clearance in cirrhosis" [17].

Furthermore, we found that $1,884(56.4 \%)$ patients showed intraoperative LA > $4.0 \mathrm{mmol} / \mathrm{L}$, and 188 (5.6\%) exceeded intraoperative LA of $10 \mathrm{mmol} / \mathrm{L}$. These rates are surprisingly high, given that LA levels $>10 \mathrm{mmol} / \mathrm{L}$ are associated with high mortality rates of $80 \%$ or more in critically ill patients $[15,18]$. In the current study on intraoperative LA exploration, patients with $\mathrm{LA}>16.7 \mathrm{mmol} / \mathrm{L}$ and $13.5-16.7 \mathrm{mmol} / \mathrm{L}$ demonstrated significantly higher 30-day mortality rates of $58.3 \%$ and $21.2 \%$, respectively.

LT is often an extremely difficult event for ESLD patients because LT recipients frequently suffer from severe hypotension, acute blood loss with extreme anemia, massive transfusion, inferior vena cava clamping, prolonged refractory hypotension with high-dose vasopressors, perturbed hemodynamics shortly after graft reperfusion, and/or pr-existing multiple organ failures, such as circulatory, respiratory, and kidney failures $[12,19]$. Additionally since initial grafts can poorly handle lactate load and may serve as a lactate-producing organ, intraoperative LA concentration is not only extremely high compared with preoperative LA, but also remains high regardless of increasing MELDs during LT surgery. It is thought that high intraoperative LA levels regardless of MELDs are likely to be due to the initial poor graft function and lactate-producing liver itself.

On the other hand, given that acidosis and hyperlactatemia can occur independently, hyperlactatemia might only be moderately predictive for acidosis. Both acidosis and lactate independently predicted mortality in critically ill patients suffering from sepsis [20]. Additionally, it has been reported that lactate clearance calculated at $6 \mathrm{~h}$ after reperfusion of an allograft was associated with the development of 


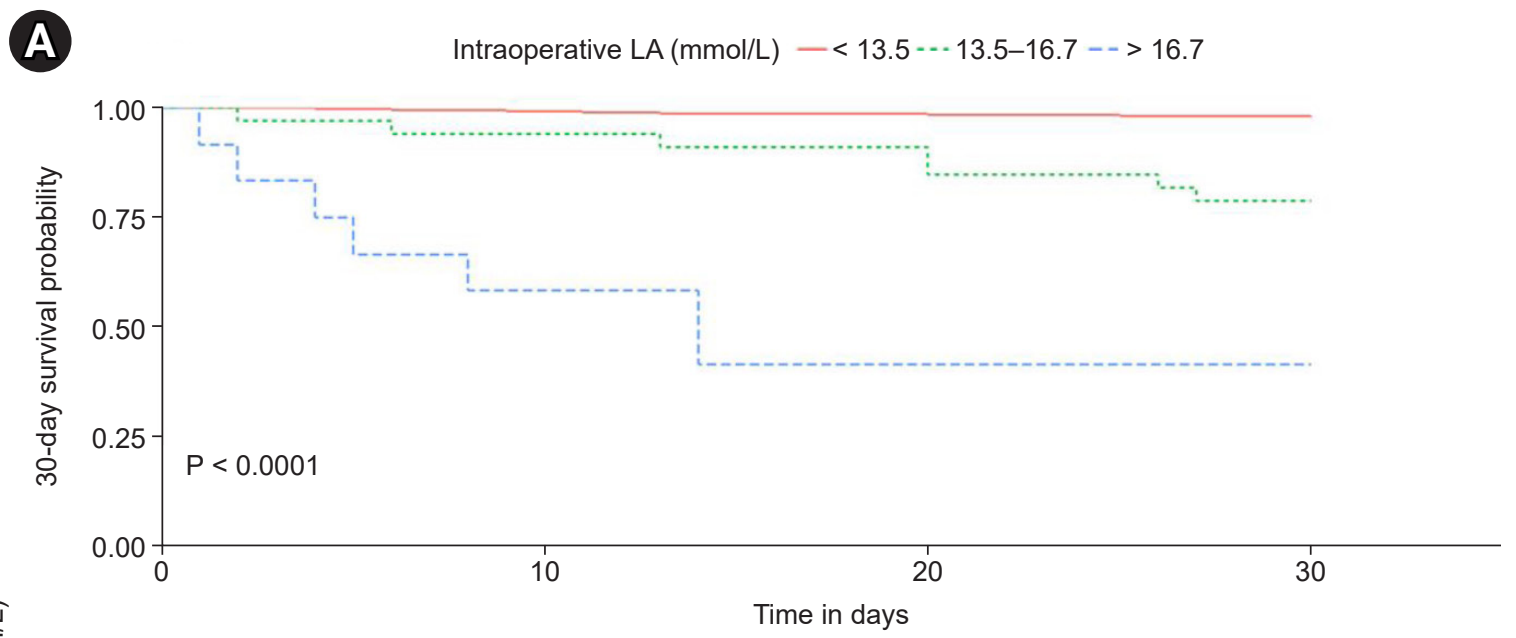

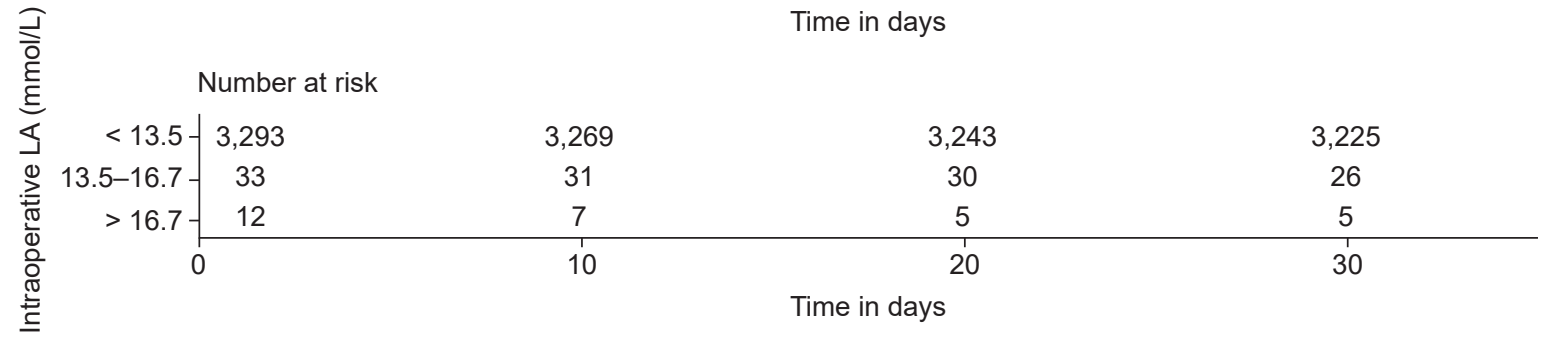

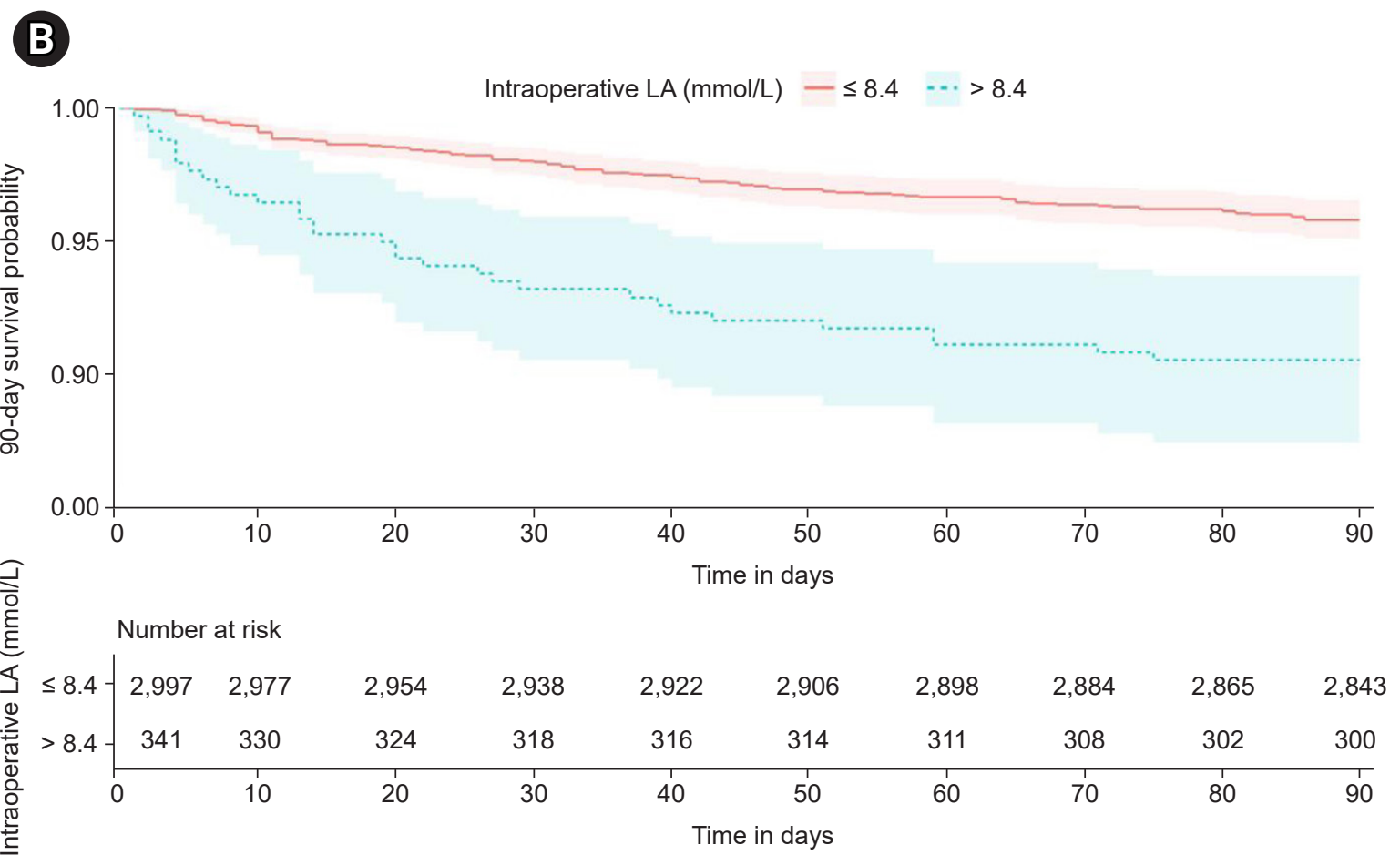

Fig. 4. Kaplan-Meier survival plot shows 30-day mortality according to intraoperative lactic acid $>16.7 \mathrm{mmol} / \mathrm{L}, 13.5-16.7 \mathrm{mmol} / \mathrm{L}$ and $<13.5 \mathrm{mmol} / \mathrm{L}$ (A) 90-day mortality according to intraoperative lactic acid > $8.4 \mathrm{mmol} / \mathrm{L}$ and $8.4 \leq \mathrm{mmol} / \mathrm{L}$ (B). LA: lactic acid.

early allograft dysfunction and in-hospital and $6 \mathrm{~m}$ mortalities after deceased donor liver transplantation [5]. In the current study, we did not evaluate the combining acidosis and hyperlactatemia and lactate clearance; therefore, fur- ther study including both of the aforementioned in a model will yield higher predictiveness of the short-term outcome in patients undergoing LT.

This study has several limitations. The enrolled patients 
are from the observational cohort study in a single center and retrospective observational design. Therefore, further prospective randomized control studies are warranted to validate our results. Additionally, higher LA resulted in higher mortality rates, but did not completely exclude factors other than LA. Therefore, future study is needed to consider non-LA factors in patients with LT.

In conclusion, in this large cohort LT study determining cutoff levels of intraoperative LA, patients with LA > 13.5 $\mathrm{mmol} / \mathrm{L}$ showed significantly higher 30-day mortality rates, and $>8.4 \mathrm{mmol} / \mathrm{L}$ was the optimal cutoff value for the 90 day mortality. Therefore, identifying intraoperative cutoffs of LA and correction of hyperlactatemia may play a potential role in lowering early mortality rates after LT.

\section{FUNDING}

This research was supported by a grant of the Korea Health Technology R\&D Project through the Korea Health Industry Development Institute (KHIDI), funded by the Ministry of Health \& Welfare, Republic of Korea (grant number : HI18C2383).

\section{CONFLICTS OF INTEREST}

No potential conflict of interest relevant to this article was reported.

\section{DATA AVAILABILITY STATEMENT}

The datasets generated during and/or analyzed during the current study are available from the corresponding author on reasonable reques.

\section{AUTHOR CONTRIBUTIONS}

Conceptualization: Gyu-Sam Hwang. Data curation: Kyoung-Sun Kim. Formal analysis: Sang-Ho Lee. Methodology: Sang-Ho Lee, Bo-Hyun Sang. Writing - original draft: Kyoung-Sun Kim. Writing - review \& editing: Gyu-Sam Hwang. Investigation: Sang-Ho Lee, Bo-Hyun Sang. Supervision: BoHyun Sang, Gyu-Sam Hwang.

\section{ORCID}

Kyoung-Sun Kim, https://orcid.org/0000-0002-6643-9177

Sang-Ho Lee, https://orcid.org/0000-0001-5943-7715
Bo-Hyun Sang, https://orcid.org/0000-0001-6890-4629

Gyu-Sam Hwang, https://orcid.org/0000-0002-3627-1107

\section{REFERENCES}

1. Kraut JA, Madias NE. Lactic acidosis. N Engl J Med 2014; 371: 2309-19.

2. Jeppesen JB, Mortensen C, Bendtsen F, Møller S. Lactate metabolism in chronic liver disease. Scand J Clin Lab Invest 2013; 73: 293-9.

3. Drolz A, Horvatits T, Roedl K, Rutter K, Brunner R, Zauner C, et al. Acid-base status and its clinical implications in critically ill patients with cirrhosis, acute-on-chronic liver failure and without liver disease. Ann Intensive Care 2018; 8: 48.

4. Cardoso FS, Abraldes JG, Sy E, Ronco JJ, Bagulho L, Mcphail MJ, et al. Lactate and number of organ failures predict intensive care unit mortality in patients with acute-on-chronic liver failure. Liver Int 2019; 39: 1271-80.

5. Kim DG, Lee JY, Jung YB, Song SH, Lee JG, Han DH, et al. Clinical significance of lactate clearance for the development of early allograft dysfunction and short-term prognosis in deceased donor liver transplantation. Clin Transplant 2017; 31 e13136.

6. Drolz A, Horvatits T, Rutter K, Landahl F, Roedl K, Meersseman $\mathrm{P}$, et al. Lactate improves prediction of short-term mortality in critically ill patients with cirrhosis: a multinational study. Hepatology 2019; 69: 258-69.

7. Wu JF, Wu RY, Chen J, Ou-Yang B, Chen MY, Guan XD. Early lactate clearance as a reliable predictor of initial poor graft function after orthotopic liver transplantation. Hepatobiliary Pancreat Dis Int 2011; 10: 587-92.

8. Orii R, Sugawara Y, Hayashida M, Yamada Y, Kubota K, Takayama T, et al. Peri-operative blood lactate levels in recipients of living-related liver transplantation. Transplantation 2000; 69: 2124-7.

9. Nishimura A, Hakamada K, Narumi S, Totsuka E, Toyoki Y, Ishizawa Y, et al. Intraoperative blood lactate level as an early predictor of initial graft function in human living donor liver transplantation. Transplant Proc 2004; 36: 2246-8.

10. Laska E, Meisner M, Wanderling J. A maximally selected test of symmetry about zero. Stat Med 2012; 31: 3178-91.

11. Kwon HM, Moon YJ, Jung KW, Park YS, Kim KS, Jun IG, et al. Appraisal of cardiac ejection fraction with liver disease severity: implication in post-liver transplantation mortality. Hepatology 2020; 71: 1364-80.

12. Kwon HM, Moon YJ, Kim KS, Shin WJ, Huh IY, Jun IG, et al. Prognostic value of B-type natriuretic peptide in liver trans- 
plant patients: implication in posttransplant mortality. Hepatology 2021; 74: 336-50.

13. Sarin SK, Choudhury A, Sharma MK, Maiwall R, Al Mahtab M, Rahman S, et al. APASL ACLF Research Consortium (AARC) for APASL ACLF working Party. Acute-on-chronic liver failure: consensus recommendations of the Asian Pacific association for the study of the liver (APASL): an update. Hepatol Int 2019; 13: 353-90.

14. Gao F, Huang XL, Cai MX, Lin MT, Wang BF, Wu W, et al. Prognostic value of serum lactate kinetics in critically ill patients with cirrhosis and acute-on-chronic liver failure: a multicenter study. Aging (Albany NY) 2019; 11: 4446-62.

15. Haas SA, Lange T, Saugel B, Petzoldt M, Fuhrmann V, Metschke M, et al. Severe hyperlactatemia, lactate clearance and mortality in unselected critically ill patients. Intensive Care Med 2016; 42: 202-10.
16. Levy MM, Evans LE, Rhodes A. The surviving sepsis campaign bundle: 2018 update. Intensive Care Med 2018; 44: 925-8.

17. Nadim MK, Durand F, Kellum JA, Levitsky J, O’Leary JG, Karvellas CJ, et al. Management of the critically ill patient with cirrhosis: a multidisciplinary perspective. J Hepatol 2016; 64: 717-35.

18. Nichol AD, Egi M, Pettila V, Bellomo R, French C, Hart G, et al. Relative hyperlactatemia and hospital mortality in critically ill patients: a retrospective multi-centre study. Crit Care 2010; 14: R25.

19. Kwon HM, Hwang GS. Cardiovascular dysfunction and liver transplantation. Korean J Anesthesiol 2018; 71: 85-91.

20. Wernly B, Heramvand N, Masyuk M, Rezar R, Bruno RR, Kelm M, et al. Acidosis predicts mortality independently from hyperlactatemia in patients with sepsis. Eur J Intern Med 2020; 76: 76-81. 